\title{
A CRÍTICA DE GADAMER E A SUBSUNÇÃO DO FATO À NORMA JURÍDICA
}

\section{THE CRITICISM OF GADAMER AND THE SUBSUMPTION OF THE FACT TO THE RULE OF LAW}

Wilson Clemente Júnior*

Ao contrário do que poderia parecer em um primeiro momento, a prestigiada obra Verdade e método - traços fundamentais de uma hermenêutica filosófica, de Hans-Georg Gadamer (2011a), não possui a pretensão de estabelecer uma doutrina hermenêutica universal do método, com o fito de cristalizar uma verdade, nem, muito menos, de arvorar-se em revanche contra a imposição hermética do método científico às "ciências do espírito" (Geisteswissenschaften).

Muito mais do que uma diferença de métodos (das ciências naturais e das ciências do espírito), há uma diferença de objetivos do conhecimento, porquanto a disputa entre os referidos caminhos não pode - ou pelo menos não poderia na visão de Gadamer - ignorar a questão primeva e fundamental posta em Verdade e Método, ou seja: como é possível a compreensão?

No transcorrer de sua investigação, o expoente alemão deixa pistas de que a hermenêutica filosófica pode contribuir na análise da subsunção do fato concreto à norma jurídica abstrata, porquanto $a$ "ordenação geral da vida através das regras do direito é bastante deficitária, necessitando de uma complementação produtiva” (GADAMER, 2011a, p. 78-79). Essa complementação se dá por meio da atividade do juízo, que promove a concreção do direito no caso sub judice.

Assim, "O juiz não só aplica a lei in concreto, mas colabora ele mesmo, através de sua sentença, para a evolução do direito (direito judicial)" (GADAMER, 2011a, p.79).

Partindo-se do pressuposto de que Gadamer está correto em sua posição original, caberiam as seguintes indagações: É possível analisar o ato de julgar do juízo através da hermenêutica filosófica de Gadamer?

Entretanto, antes de voltar a atenção para o ato de julgar em si e a crítica formulada pela hermenêutica filosófica àquele, necessário se faz, primeiramente, acompanhar os passos do eminente professor que, em busca da justificação filosófica para a experiência da verdade,

\footnotetext{
* Graduação em Direito pelo Centro Universitário de Sete Lagoas (1996) e graduando em Filosofia pela PUC Minas (2015).
} 
percorre-a na arte, na compreensão das ciências do espírito e na fundamentação ontológica da hermenêutica da linguagem.

Na primeira parte da reverenciada obra Verdade e método I - traços fundamentais de uma hermenêutica filosófica -, Gadamer analisa a experiência da verdade em relação à obra de arte e conclui ser inapropriada a utilização do método indutivo das ciências da natureza nas ciências humanas, em razão de sua inadequada metodologia, no particular.

Gadamer (2011a) argumenta ainda no sentido de que a obra de arte não se esgota com o passar do tempo. Sua compreensão implica uma mediação histórica para ser uma experiência da verdade. Assim, ela não se baseia em um método, e isso vale para todas as espécies de arte, como a música, o teatro, a arquitetura e a literatura.

Destarte, se a experiência da verdade pode ocorrer na literatura, evidentemente tal verdade pode emergir e ser aplicada na hermenêutica. O que diferiria a linguagem científica, da poética, citada aqui apenas a título de exemplo, seria somente a diversidade da pretensão de verdade, vez que cada uma, a seu modo, possuiria a potência de produzir na linguagem seus respectivos efeitos.

Contribuição significativa foi dada por Heidegger (1889-1976) ao afirmar que a base da hermenêutica da facticidade era fundada no Dasein ${ }^{l}$, que representa a base ontológica do questionamento humano e não no "cogito" puro, ou seja, o lugar do questionamento é a existência humana e não o cogito fenomenológico.

Em Ser e tempo, Heidegger (2011) revela que todo sentido do ser e da objetividade só se torna compreensível e demonstrável a partir da temporalidade e historicidade de Dasein. Assim, o ser é determinado a partir do horizonte do tempo.

A única coisa que possibilita toda compreensão do ser é o próprio fato de que existe um "pré" (dá), uma clareira no ser, isto é, a diferença entre ser e ente.

A "guinada" (kehre) é a realização do movimento da reflexão transcendental, já que o Dasein está lançado (Geworfenheit) no mundo e possui como horizonte sua própria finitude. Desse modo, a hermenêutica da facticidade ultrapassou o conceito de espírito do idealismo clássico, como campo temático da consciência transcendental, ao considerar a pertença do sujeito ao próprio objeto. Superou-se a relação sujeito-objeto, porquanto compreender tornou-

\footnotetext{
${ }^{1}$ Usualmente o termo Dasein é traduzido por "Ser-aí", todavia, optou-se pela terminologia alemã de "Ser e Tempo", por sofrer a referida tradução várias críticas por não abranger completamente o sentido originário empregado por Heidegger, como modos de ser do homem, abarcando as dimensões da disposição afetiva (Befindlichkeit), da compreensão (Verstehen) e do discurso, como "ser com" (Mit sein). Aula ministrada pelo prof. Ibraim Vitor de Oliveira da disciplina Grupo de Estudo, técnica e linguagem em Heidegger em 01 de outubro de 2013.
} 
se a forma originária de realização de Dasein, que é ser-no-mundo (HEIDEGGER, 2011).

Gadamer (2011a), então, embasa-se na estrutura existencial de Dasein como premissa insuperável para formular a compreensão na tradição histórica, eis que Heidegger (2011) já havia registrado, ao tratar da questão do esquecimento do Ser, que se deveria voltar o olhar para as coisas mesmas.

A tarefa hermenêutica se converte em um questionamento pautado na coisa em questão, na coisa em si, com a abertura para a opinião alheia ou para o que diz o próprio texto, não se abstendo dos posicionamentos próprios, mas os suspendendo temporariamente, para se encontrar sempre codeterminado por aqueles.

A pré-estrutura da compreensão exige do intérprete a permissão para que o texto fale, para que a alteridade do "ser-aî" se manifeste. Lado-a-lado, a compreensão desejável procura não antecipar, mas sim tornar-se consciente de seus preconceitos para compreender a partir das próprias coisas.

A análise da história do conceito da palavra preconceito revela que somente no Esclarecimento (Aufklärung) é que a mesma recebeu matiz negativo.

O Esclarecimento, como um movimento filosófico, prestigiou o uso sistemático da razão, com o intuito de precaver-se contra o erro, e voltou-se contra o preconceito, a tradição e a autoridade, pois esses poderiam levar à obediência cega.

A origem da palavra preconceito remonta a (Vorurteil), que quer dizer um juízo (Urteil) que se forma antes do exame definitivo. Assim, uma pré-decisão jurídica (uma liminar) seria um preconceito, já que proferida antes da decisão definitiva.

O valor da autoridade é resgatado por Gadamer (2011a), ao destacar que não se trata de abdicação da razão, mas sim de reconhecimento e de conhecimento, eis que se reconhece que o outro possui melhor juízo e visão, motivo pelo qual seu juízo precede/tem primazia em relação ao outro. Por isso que a autoridade não deve ser outorgada, mas sim alcançada. $\mathrm{O}$ reconhecimento da autoridade é, portanto, um ato livre da própria razão.

A tradição, a seu turno, é tão livre como a destruição e a inovação e integra-se ao novo. Para Gadamer (2011a), o fenômeno hermenêutico se movimenta entre o desconhecido e o conhecido, que a tradição traz na objetividade da distância e na pertença de cada um ao contexto histórico. Esse é o lugar da compreensão (Zwischen).

Ao se trabalhar um texto, o intérprete deve partir da concepção prévia de perfeição, que determina a necessidade de o intérprete buscar diligentemente e de forma verdadeira toda a unidade de sentido que se pode obter no texto, a fim de ser alcançada a máxima coerência e 
coesão possíveis. A compreensão, dessa forma, revela seu caráter produtivo e não meramente reprodutivo. Essa distância temporal da sua produção hermenêutica é pensada graças ao giro ontológico que Heidegger deu à compreensão como um existencial, aplicando-o ao modo de se constituir do ser.

A importância da distância temporal é revelada na medida em que o transcorrer do tempo traz à tona os verdadeiros preconceitos, levando para o rio do esquecimento os demais. O que destaca o preconceito, fazendo emergi-lo é o encontro com a tradição, o encontro de si com a alteridade, pois a compreensão se inicia na interpelação de algo, logo, a condição hermenêutica pressupõe a suspensão completa dos próprios preconceitos.

Para se evitar recair no erro dos antecessores e seguindo a estrutura ontológica de Dasein como compreensão, Gadamer (2011a) trabalha com o princípio da história efeitual, segundo o qual todo intérprete encontra-se historicamente condicionado e ainda que tenha consciência dessa sua condição, isso não o torna incondicionado. Logo, sua situação hermenêutica é afetada pela tradição através de preconceitos herdados, da mesma forma que outros preconceitos serão projetados para o futuro.

Como que em um trabalho arqueológico, onde se pergunta pela origem de vários institutos, Gadamer (2011a) destaca que a aplicação, como mediação entre passado e presente, sempre esteve presente em um processo unitário da compreensão, tanto na hermenêutica jurídica quanto na teológica. Não se compreende para posteriormente aplicar. O ato é simultâneo.

Tanto um juiz quanto um pastor, no ato de compreender uma lei ou anúncio, deve considerar a tensão existente entre o texto e o alcance de sua aplicação no momento concreto da compreensão, na judicatura ou na pregação. A compreensão deve concretizá-la em sua validez jurídica, da mesma forma que a hermenêutica teológica deve indicar/proporcionar a bem-aventurança. Aplicar, portanto, é exercer efeito e requer sempre compreensão.

Para Gadamer (2011a), assim como a hermenêutica aristotélica, em sua deliberação ética $^{2}$, a hermenêutica jurídica trabalha com a atualidade, eis que não só o intérprete como também o juiz investigam o sentido da norma ou lei, ao partirem de um caso concreto, considerando sempre a vida atual para aplicar o horizonte do texto. Assim, com a

\footnotetext{
${ }^{2}$ A deliberação aristotélica, em relação à virtude do saber moral, exige sempre a consideração da situação concreta para realizar/atualizar imediatamente o preceito ético (a norma geral), no caso específico. O saber não é simplesmente concretizado no fazer, mas aplicado com esmero e cuidado para se atingir a justa medida. A norma ética não é determinada antes do tempo e não existe padrão fixo de concreção. Todas as circunstâncias do caso específico devem ser ponderadas (GADAMER, 2011a).
} 
compreensão stricto sensu, é garantida a sobrevivência contínua do direito e salvaguardada toda a tradição jurídica.

A forma ideal de acesso ao texto é através do modelo da dialética platônica da pergunta e da resposta, eis que ao se perguntar autenticamente, há que se colocar em suspenso o que se pensa como resposta (seus preconceitos), para dar abertura ao diálogo.

O texto a ser interpretado é sempre uma resposta a alguma pergunta originária. Ao se indagar e descobrir essa pergunta originária, capta-se o sentido do texto e se conquista o horizonte hermenêutico.

Ao mesmo tempo, o texto é também pergunta ao intérprete, onde a tradição apresentase em linguagem. Para compreender a palavra da tradição, o intérprete deve colocar em aberto a própria opinião e suspender seus preconceitos, realizando sempre a automediação histórica do presente com o passado e buscando verdadeiramente pela validade de sentido do texto, através da concepção prévia de completude, deixando-se ser interrogado.

A reconstrução da pergunta originária, assim, encontra-se dentro da resposta da pergunta que é imposta pela tradição inserta no texto. No ultrapassar essa mera reconstrução (verdadeira exigência hermenêutica) e cotejar com o horizonte próprio, o intérprete/juiz amplia sua experiência hermenêutica e alcança a fusão de horizontes.

A compreensão correta inicia-se com o fato de o intérprete ter consciência de sua inserção histórica na tradição, momento em que sua entrada no círculo hermenêutico dá-se sempre de forma condicionada historicamente.

A síntese do processo de compreensão é a fusão de horizontes (do texto e do próprio intérprete). É no pôr-se de acordo na linguagem, que se torna possível identificar os preconceitos legitimados. Essa é a realização da essência da linguagem.

A dialética metafísica e a hermenêutica possuem algo em comum que é o elemento especulativo. A noção de especulativo baseia-se na ideia do espelhamento. Especulativo é quem não se conforta em uma determinação estável e disponível, mas aquele que sabe refletir, que conhece, hegelianamente dizendo, o "em si" como um "para mim". Não é uma atribuição unívoca de uma determinação do sujeito, e revela a estrutura especulativa da relação hermenêutica com a linguagem, tanto no falar cotidiano quanto na linguagem poética. (GADAMER, 2011a).

Por isso, a compreensão de um texto encontra apenas uma perfeição relativa e especulativa, pois se assemelha à estrutura do intérprete - ser, por excelência, finito e histórico - na medida em que o movimento exegético nunca é concluído integralmente, revelando uma 
perfeição da compreensão sempre relativa.

Logo, toda apropriação da tradição é limitada historicamente, por isso distinta de outras anteriores e futuras, pois pertence a uma visão específica da própria coisa. Mudar e conservar-se o mesmo, aí está o caráter especulativo do conteúdo da tradição.

Segundo Gadamer (2011a), Platão afirma que o bem (agathon) é inapreensível, tanto que toda vez em que se pretende apreender a essência do bem, esse se refugia no belo (kalon). Por sua vez, o belo se mostra e se deixa apreender facilmente. Sua característica principal é o mostrar-se, aparecer-se. É a caracterização imediata daquele para a alma humana. Por isso o belo atrai imediatamente.

As virtudes humanas, por outro lado, exigem um olhar atento e percuciente para serem distinguidas na confusão obscura dos fenômenos mundanos. É relativamente fácil deixar-se enganar por simulacros camuflados de virtude, porque essa não possui luz própria, o que engana muitos. A beleza em si, não. Ela brilha e se mostra inequivocamente. É o ser mais reluzente, que um mero golpe de olhar identifica e faz admirar. Ela atrai o desejo da alma e aquilo que não participa da beleza, com ela não pode ser confundido.

O belo em si, então, brilha por si próprio e dele nada se pode tirar ou acrescentar sem que lhe traga prejuízo. Exemplos disso se encontram facilmente na música, escultura e poesia. O brilho manifesta a verdadeira essência do belo, que tem seu modo de ser no "aparecer". A luz de sua verdade é imediatamente apreendida e ilumina o que está ao redor. (GADAMER, 2011a).

Quanto à possibilidade da hermenêutica filosófica de Gadamer contribuir com seu olhar crítico sobre o ato judicial de julgar, verifica-se que não se vislumbra qualquer impedimento do jus-filosófico, eis que o Direito se socorrer de outras áreas do conhecimento, mormente a filosofia, para realizar o seu mister, ou seja, a pacificação social com justiça. Dessa maneira, quando o magistrado se socorre de peritos-técnicos antes de sentenciar em um processo, nada mais faz do que dialogar com outros domínios de conhecimento, com o fito de sair da perplexidade para melhor exercer a jurisdição.

Assim, porquanto Gadamer não seja jurista “de profissão", nada impede que seu olhar percuciente e analítico produza frutos em prol de toda a comunidade acadêmica e jurídica, sob pena de se desprezar valorosas contribuições de eminentes pensadores, única e exclusivamente por não terem formação estrita em determinada área, o que, com a devida venia, não é razoável prosperar.

Tanto Schleiermacher quanto Dilthey não foram juristas, e é inconteste a influência de 
ambos na hermenêutica lato sensu (LAWN, 2010), o que atinge, por óbvio, a hermenêutica jurídica. Dessarte, nada impede que o Direito se desenvolva com as contribuições de novos processos de compreensão.

Ressalta-se, ainda, que o modo de "ser" do ser, para Gadamer (2011a), é ser hermenêutico e se dá na linguagem, logo, na base estrutural do homem, em sua categoria ontológico-existencial fundamental, está presente o mundo como linguagem e o caráter hermenêutico do ser humano como pré-condição - o que por óbvio alcança o "mundo jurídico" e seus jogos de linguagem próprios.

Autorizada a crítica da hermenêutica filosófica de Gadamer no papel produtivo no Direito, resta indagar como se perfaz essa contribuição na atividade jurisdicional, no entender do filósofo de Marburgo.

Quando se encontram ser e ente (juiz e norma), há sempre um momento de investigação do intérprete em busca da verdade, no sentido de que o ente não se revela por completo - a verdade por inteiro jamais é alcançada -, permanecendo sempre com múltiplas facetas ocultas.

A palavra verdade pode ser relacionada ao termo grego aletheia e remonta à Grécia antiga $^{3}$, tendo sua notória aparição no Livro X, de A República de Platão, onde é revelada a existência de um rio chamado Letes, encarregado de trazer esquecimento para as almas que tocassem/bebessem suas águas (PLATÃO, 2010, p. 415). O prefixo - $a$ - é empregado para dar conotação negativa (a-letheia), fazendo surgir não-esquecimento, não-ocultação, desocultamento, que originou sua tradução para o português como verdade, o que é apontado por muitos autores como inadequado.

Não é sem motivo que Gadamer, resgatando os ensinamentos de Heidegger, trabalha a palavra aletheia como sendo a dimensão em que o ser se desvela. Outra dimensão existente é aquela na qual ele se retira, não sendo apreensível em parte alguma no pensamento grego (GADAMER, 2012, p. 20).

A verdade absoluta não é acessível ao homem. Nesse sentido, lembra-se do primeiro Wittgenstein, que pensava ter encontrado a verdade definitiva ao "solucionar" todos os problemas filosóficos em sua obra Tractatus Lógico-Philosophicus. Na Introdução da referida obra, o autor chegou a asseverar que a verdade dos pensamentos aqui comunicados pareceme intocável e definitiva. Portanto, é minha opinião que, no essencial, resolvi de vez os

\footnotetext{
${ }^{3}$ A primeira aparição da palavra Lete, que em grego significa "esquecimento", é remetida a Aristófanes, em sua obra As rãs. (LOPES, 2010, p. 415).
} 
problemas (WITTGENSTEIN, 2010, p. 133). A grandiosidade do referido filósofo da linguagem e o seu amor à verdade o fez, aproximadamente cinco anos após redigir essas palavras, desdizer-se e assumir nova perspectiva teórica na interpretação da linguagem. A verdade absoluta mais uma vez não se "deixou" ser apreendida pelo homem.

As inúmeras faces do objeto, neste caso a lei, revelam a necessidade de o magistrado procurar inclusive por sentidos ocultos da norma, eis que a consciência hodierna revelou ao legislador a "ingenuidade" de se pensar a possibilidade de tutela de direitos com base na verdade absoluta ${ }^{4}$. Tanto é assim, que surgiram os juízos de verossimilhança e juízos de probabilidade como instrumentos de tutela e de efetividade do direito, como no caso de antecipação dos efeitos da tutela, ação monitória e inversão do ônus da prova no Código Consumerista (MARTINS-COSTA; BRANCO, 2002, p. 13).

A contribuição significativa das hermenêuticas filosóficas para a atividade jurisdicional passa pelo reconhecimento de que a dialética gadameriana permite a conciliação entre opostos, o diálogo entre passado e presente, tradição e atualidade, a reconstrução da ruína do passado para se edificar uma estrutura atualizada, criando um projeto que muda a base a partir da qual novas regras jurídicas são criadas, sem, necessariamente, instituir um novo direito.

A compreensão jurídica da norma posta em análise representaria a fusão de horizontes, onde intérprete e objeto estariam lançados-no-mundo, dialogando entre si em um contexto histórico e atuando reciprocamente no horizonte hermenêutico do outro, a fim de expandir o limite hermenêutico para além de si próprio, com o fito de se alcançar a adequação material da lei ou ato normativo com a Constituição Federal e, consequentemente, definir o sentido de sua aplicação para se alcançar a justiça. Aqui vale lembrar, por oportuno, que a compreensão, a interpretação e a aplicação para Gadamer (2011a) ocorrem em momentos simultâneos e não sucessivos.

O desafio de se buscar a pacificação social com justiça levará o intérprete à dialética da pergunta e da resposta onde soluções prontas não existem, dadas as particularidades de cada caso e do próprio horizonte do intérprete, mutável por excelência. Destarte, se fosse possível ao magistrado sentenciar o mesmo processo duas vezes em contextos históricos diversos, segundo Gadamer (2011a), certamente haveria duas fundamentações distintas,

\footnotetext{
${ }^{4}$ Nem mesmo as ciências da natureza trabalham com o conceito de verdade absoluta. As ciências experimentais fundam-se em proposições e essas têm intrinsecamente em sua essência a possibilidade de sempre serem falseadas.
} 
emergindo diferenças, ainda que sutis, em sua resolução (não descartada a hipótese de soluções díspares, o que não seria nenhum absurdo), dada a dinâmica existente no horizonte hermenêutico do julgador e a atuação da historicidade naquele ${ }^{5}$.

Por outro lado, muito embora essa compreensão seja aperfeiçoada, porquanto leva em consideração o sopesar dos próprios preconceitos em cotejo com os preconceitos trazidos pela tradição jurídica presente na norma, a compreensão é sempre especulativa, no sentido de que a relação hermenêutica nunca se encontra acabada, em estado estático, dado o círculo hermenêutico, o que é corroborado pelo conceito de aletheia trabalhado pelo filósofo de Marburgo, e da própria condição finita e histórica do homem, eis que não existe Direito fora de contexto.

O julgamento ideal para Gadamer (2011a) seria aquele em que o julgador ouve a tradição que lhe vem à fala através da norma, questiona-se, conhece-se, considera seus préjuízos sopesando-os de maneira que, ao buscar a solução mais justa para o caso sob análise, não desconsidera seu caráter histórico, finito e falível (acrescentar-se-ia), com o objetivo de não se acomodar com respostas automáticas e (no momento da prolação da decisão) irrefletidas, embora em algum momento no passado, ou em julgamentos anteriores, tivessem sido ponderadas. Segundo o autor, o magistrado não pode encontrar a solução da causa em um momento e sua fundamentação de decidir em outro distinto. Exige-se que a decisão seja lançada somente quando a fundamentação/compreensão for atingida, não se podendo falar em encontrar a decisão/solução antes da fundamentação.

Nesse ponto específico, as anedotas de Piero Calamandrei (1995) no sentido de que algumas vezes o juiz parte da conclusão para chegar às premissas, em razão de uma "misteriosa e clarividente virtude de intuição, que se chama senso de justiça" (CALAMANDREI, 1995, p. 178), não alcançam guarida na hermenêutica filosófica.

O estar-lançado-no-mundo traz um sentimento de pertença ao julgador em relação às partes, à norma e ao objeto sob litígio, de maneira que sua vivência impõe um real sentimento de solidariedade e preocupação, esquivando-se de soluções prontas. $\mathrm{O}$ julgador nesse ponto deixa de ser simplesmente aquele que conhece as leis e realiza a subsunção com maestria lógico-matemática para ser um ser-com, um ser-para-o-outro, sendo afetado pela alteridade do outro, na medida em que pensa-com-o-outro em busca da justa solução - circunstâncias que não são homenageadas pelos métodos hermenêuticos tradicionais aplicáveis ao Direito até

\footnotetext{
${ }^{5}$ Historicidade não se confunde com temporalidade. Enquanto aquela é a sucessão de eventos significativos no tempo, a temporalidade é apenas a sucessão cronológico-temporal (MARTINS-COSTA; BRANCO, 2000).
} 
então.

Para se evitar o malogro do subjetivismo, é importante lembrar que em um Estado Democrático de Direito, como a República Federativa do Brasil, existem princípios jurídicos que norteiam os julgadores, como os princípios constitucionais da dignidade da pessoa humana, dos valores sociais do trabalho e da livre iniciativa, do pluralismo político, da construção de uma sociedade livre, justa e solidária, da promoção do bem de todos, sem qualquer forma de discriminação e do princípio da igualdade ${ }^{6}$, apenas para citar alguns.

Relacionando as explanações acima, pode-se arriscar dizer que os referidos princípios constitucionais seriam, na linguagem de Gadamer, uma espécie de "preconceitos jurídicos" dotados, em decorrência do Poder Constituinte Originário, de presunção absoluta de legitimidade, eis que cristalizados na tradição jurídica.

Assim, mesmo em se tratando de máximas normativas condensadas, é perfeitamente previsível e até natural que ainda reste algum espaço para o preenchimento do conteúdo dos referidos princípios insertos na Constituição da República, de 1988, o que seria tarefa da hermenêutica esclarecer. De toda maneira é incontestável o fato de que seus contornos já foram estritamente postos pelo Constituinte Originário, logo, inequívoco o fato de ter ocorrido um pré-juízo na eleição dos aludidos princípios.

A fusão de horizontes encontrada - a exemplo do que faz o "belo" na cultura grega e em relação à obra de arte, que brilham por si, independentemente de qualquer artifício -, destacar-se-á no arcabouço jurídico, e a decisão acertada tomará para si esse reluzir da verdade atingida historicamente (mesmo sendo mutável e dinâmica), revelando a justiça da decisão ao se apresentar consentânea e coesa com os preconceitos (jurídicos) legítimos, propiciando a evolução do Direito através dos julgados, resguardando-se, a seu turno, a tão prestigiada e necessária segurança jurídica, o que não se confunde com decisões uníssonas.

Interessante registrar que o princípio do pluralismo homenageado em vários dispositivos na Carta de Outubro/ $1988^{7}$, ressalta a tolerância ao dissenso, por estar cônscia da incompatibilidade existente entre linguagem, democracia e discurso único. O monopólio do pensar hermético não condiz com uma República, ou seja, com um estado governado por representantes eleitos pelo povo, para o povo, com transitoriedade de mandatos, predominância do interesse público, prestações de contas e exigência de explicitação da

\footnotetext{
${ }^{6}$ Constituição da República Federativa do Brasil/1988, art. $1^{\circ}$, incisos III, IV e V, art. $3^{\circ}$, inciso I e IV, e art. $5^{\circ}$, caput e inciso I, respectivamente (BRASIL, 1988).

7 Além dos dispositivos já citados, acrescentem-se, ainda, os que tratam da liberdade de expressão, de consciência, de crença e de associação, citados apenas a título de exemplo.
} 
motivação nas decisões tomadas, tudo sob o império da lei. Isso se reflete também nas decisões judiciais, vez que perfeitamente possível encontrarem-se julgados com soluções distintas igualmente acertadas sobre um mesmo assunto, de acordo com cada caso concreto.

A verdade das ciências humanas, por sua vez, é dotada de uma validade sui generis, típica das ciências do espírito, eminentemente humanística - objetiva, mas não objetivante, nem fixa.

Por serem os Tribunais palcos dos maiores dramas humanos, nada mais consentâneo com a justiça do que um olhar comprometido com a alteridade, que não se contenta com respostas prontas e acabadas, pelo contrário, questiona-se incessantemente e reconhece a estreiteza de todo conhecimento, eis que histórico.

\section{Referências}

BRASIL. Constituição da República Federativa do Brasil de 1988. Diário Oficial da União, Brasília, 5 out.1988. Disponível em:

<http://www.planalto.gov.br/ccivil_03/Constituicao/Constituicao.htm> Acesso em: 04 out. 2015.

CALAMANDREI, Piero. Eles, os juízes, vistos por um advogado. São Paulo: Martins Fontes, 1995.

GADAMER, Hans Georg. Hermenêutica em retrospectiva. 2. ed. Petrópolis: Vozes, 2012.

GADAMER, Hans-Georg. Verdade e método I: traços fundamentais de uma hermenêutica filosófica. 11. ed. Petrópolis: Vozes, 2011a.

GADAMER, Hans-Georg. Verdade e método II: complementos e índice. 6. ed. Petrópolis: Vozes, 2011b.

HEIDEGGER, Martin. Ser e tempo. Tradução de Márcia Sá Cavalcante Schuback. 5. ed. Petrópolis: Vozes, 2011.

LAWN, Chris. Compreender Gadamer. 2. ed. Petrópolis, RJ: Vozes, 2010.

LOPES, Daniel Rossi Nunes. Nota de rodapé número 98. In: PLATÃO. A República. Tradução e organização de J. Guinsburg; revisão comparada de Luís Alberto Machado Cabral, com introdução de Maria Sylvia Carvalho Franco. São Paulo: Perspectiva, 2010.

MARTINS-COSTA, Judith; BRANCO, Gerson Luiz Carlos. Diretrizes teóricas do novo código civil brasileiro. São Paulo: Saraiva, 2002.

WITTGENSTEIN, Ludwig. Tractatus logicus-philosophicus. 3. ed. São Paulo: Editora da Universidade de São Paulo, 2010. 